\title{
EMOTIVIDADE VERSUS RAZÃO NO PROCESSO DO CONHECIMENTO*
}

\author{
EMOTION VERSUS REASON IN THE PROCESS OF KNOWLEDGE
}

\author{
Balduíno Andreola** \\ Doutor em Ciências da Educação pela Université Catholique de Louvain |Bélgica \\ E-mail: balduinoandreola@yahoo.com.br
}

\begin{abstract}
REVISTA PEDAGÓGICA
Revista do Programa de Pós-graduação em Educação da Unochapecó | ISSN 1984-1566 Universidade Comunitária da Região de Chapecó | Chapecó-SC, Brasil Como referenciar este artigo: ANDREOLA, Balduíno. Emotividade versus razão no processo do onhecimento. Revista Pedagógica, Chapecó, v.16, n.32, p. 81-99, jan./jul. 2014.
\end{abstract}

RESUMO: O Iluminismo, como movimento de ideias, representou grandes avanços, não apenas nos campos filosófico e científico, mas também na educação, na cultura, na política, na economia e no processo histórico de emancipação humana. Todavia, com a absolutização da razão e do indivíduo, desprezando outras dimensões da existência humana, o Iluminismo promoveu o racionalismo, o individualismo, a competição, a especulação capitalista, o colonialismo, a depredação da natureza, guerras sempre mais violentas, aumento das desigualdades, da pobreza, da fome e da violência a tal ponto que numerosos pensadores caracterizam o mundo atual como a anticivilização da barbárie, e nos desafiam à promoção de outras dimensões do humano, expressas pelas "razões do coração". Este artigo baseia-se sobretudo nas contribuições do filósofo existencialista russo Nicolas Berdiaeff, em sua obra "Cinco Meditações sobre a Existência", numa interlocução, porém, com outros pensadores, que dedicaram sua luta histórica à construção de outro mundo possível, mais humano e solidário.

PALAVRAS-CHAVE: Iluminismo. Razão. Emotividade. Educação. Conhecimento.

\begin{abstract}
The Enlightenment represented great advances in the philosophic and scientific field, but also in the education, culture, politics, economy, and in the process of emancipation of the humanity. However, with the absolutism of the reason, minimizing or disdaining other dimensions of the human existence, the Enlightenment promoted the rationalism, the individualism, the competition, the speculation, the colonialism, the depredation of the nature, wars always more violent, the increasing of the inequalities, misery, famine and violence, to such a point that numerous thinkers characterize today's world as the anti-civilization of the barbarity, at the same time that they defy us to a rediscovery and promotion of other human dimensions expressed by the "reasons of the heart". This article is based mainly in the contributions of the Russian existentialist Nicolas Berdiaeff, in his work "Five Meditations about the Existence", in a dialogue, however, with other thinkers and educators of our time who dedicated their works and their historic fight to the utopia of the building of "another possible world", more humane and sympathetic. KEYWORDS: Enlightenment. Reason. Emotion Education. Knowledge
\end{abstract}




\footnotetext{
* Este artigo contou com a colaboração do bolsista de iniciação científica Ronaldo Silva Lopes, acadêmico do curso de Psicologia; das bolsistas voluntárias Bruna Carvalho dos Santos, acadêmica do curso de Pedagogia, e Alice Rodrigues de Almeida, licenciada em Letras.

** Doutor em Ciências da Educação pela Université Catholique de Louvain (Louvain-La-Neuve) - Bélgica (1985). Professor Titular da Universidade Federal do Rio Grande do Sul. Atualmente professor do Mestrado em Educação do Centro Universitário La Salle - UNILASALLE de Canoas - RS
}

\section{INTRODUÇÃO}

Para que a gente escreve, se não é para juntar nossos pedacinhos? Desde que entramos na escola ou na igreja, a educação nos esquarteja: nos ensina a divorciar a alma do corpo e a razão do coração. Eduardo Galeano (1995)

Renascença ou Renascimento, como época e como movimento histórico, significou, numa concepção mais tradicional, um "renascimento" ou revitalização dos valores e das conquistas da antiguidade greco-latina nos campos da filosofia, das artes, das letras e da cultura em geral. Todavia, esse "renascimento" traz em si um sentido bem mais profundo e radical: o de "renascimento do espírito do homem" (Reale \& Antiseri, vol. 3, 2005, p. 12). Segundo esses autores, a tese que mais vigorou, durante muito tempo, de "oposição" e de "ruptura", com relação à Idade Média, não se sustenta mais (idem, p. 9-13). O extremo oposto, de "continuidade", também não, prevalecendo a interpretação da "diversidade", conforme a mesma fonte (idem. p. 12):

Mas entre a contrariedade e a homogeneidade, existe a "diversidade". Ora, dizer que a Renascença é uma época "diversa" da Idade Média, não apenas permite distinguir as duas épocas sem contrapô-las, mas também identificar facilmente seus nexos e suas tangências, bem como suas diferenças, com grande liberdade crítica.

A "diversidade" maior consiste em que, enquanto a Idade Média colocava no centro o "divino" como fundamento da vida, do pensamento e da organização política, os renascentistas pretendiam que o centro e a base fosse o "humano". Ao "teocentrismo" contrapunham o "antropocentrismo". A um pensamento predominantemente teológico, de uma verdade "revelada", sucedia o pensamento filosófico e científico, construído pela inteligência humana. No campo filosófico, a expressão mais clara de tal tendência seria o "cogito: ergo sum" (eu penso: logo, existo) de Descartes. No campo científico, bastaria lembrar Kepler, Newton e Galileu Galilei. Sem esquecer que a "reviravolta" aconteceu também no campo teológico, com Lutero e a Reforma. Lutero pagou o preço no campo eclesiástico, mas as reações eclesiásticas aconteceram também nos campos da filosofia e da ciência, como nos casos de Galileu, chamado para retratar-se de sua teoria "heliocêntrica", e Descartes, que, ao sabê-lo, ocultou um livro que estava para publicar. As reações da Igreja medieval e tridentina se prolongaram através dos horrores da Inquisição, tornando-se menos grosseiras e mais sofisticadas, posteriormente, nos procedimentos da Congregação do Santo Ofício, no Vaticano.

A proclamação da autonomia do pensamento humano evoluiu, através dos séculos XV, XVI e XVII, atingindo seu ápice no século XVIII, com a absolutização 
1 Filósofo existencialista russo nascido em Kiev, em 1874, e falecido em Paris, em 1948. Em 1925 teve que exilar-se, indo primeiramente para a Alemanha e posteriormente para a França. Segundo a Enciclopédia Filosófica italiana (1957, vol. I, p. 638): “ Participou do Movimento de Mounier, do qual recebeu, em parte, a inspiração para um personalismo socialista e para a crítica do mundo burguês e do capitalismo". Foi grande amigo e parceiro de lutas de Mounier, que proferiu dele memorável elogio fúnebre. Nas citações de sua obra "Cinco Meditações sobre a Existência”, mantenho a ortografia da tradução portuguesa de 1961. da "Razão", no fenômeno cuja imensa complexidade foi sintetizada numa palavra: "Iluminismo", "iluminação" ou então "esclarecimento", que significa a afirmação da autonomia da razão como caminho para a emancipação humana. Essa defesa da razão autônoma foi uma das grandes conquistas da humanidade, que abriu o caminho para um extraordinário desenvolvimento humano em quase todos os campos. Ao mesmo tempo, todavia, à medida que o Iluminismo absolutizou a razão, fechou os caminhos para o desenvolvimento de outras potencialidades humanas, tanto na linha da ação quanto da elaboração teórica. A razão absoluta passou a desconhecer "as razões do coração". O racionalismo moderno, que, segundo muitos estudiosos, teria suas raízes no "cogito" cartesiano, evoluiu como razão filosófica, científica, técnica e instrumental. Ao invés de uma razão do ser humano na sua totalidade, afirmou-se como razão do indivíduo, como seus desdobramentos, na afirmação da liberdade individual, da propriedade privada, da competição, do lucro e na concentração dos bens como privilégio de uma minoria, no sistema capitalista. "A liberdade do liberalismo - escreveu Mounier - é a liberdade do mais forte”. Não se trata de meras abstrações, porque o Liberalismo, filosofia do Capitalismo, tornou-se razão filosófica de todas as formas de colonialismo, de imperialismo, de consumismo desmesurado, de concentração ilimitada dos bens, de guerras sempre mais violentas, com o aumento da pobreza, da miséria, da fome e da violência no mundo. Tanto que muitos pensadores de renome internacional caracterizam a sociedade humana atual como uma anti-civilização da barbárie (Andreola, 2011, p. 316-320). Ao mesmo tempo, contudo, muitos desses pensadores dedicaram ou dedicam suas vidas, tanto na linha da práxis quanto da elaboração teórica, à construção de outro mundo possível, como civilização humana da solidariedade. Tanto na vida quanto na ação e no pensamento, muitos autores de nossa época, sem desmerecer as grandes conquistas da razão humana, nos campos da filosofia, da ciência, da tecnologia e da economia, passaram a dedicar importância igual às "razões do coração", grande intuição precursora de Pascal.

Nesta linha de pensamento, ocorre-me citar o grande filósofo existencialista russo Nicolas Berdiaeff' ${ }^{1}$. No primeiro capítulo de seu livro "Cinco Meditações sobre a Existência" (Berdiaeff, 1961), depois de afirmar que São Boaventura resolveu o problema das relações entre conhecimento filosófico e fé de maneira diversa da de São Tomás, declara: "Esta opinião parece-me mais justa; mas não ignora menos a tragédia do filósofo, a do conhecimento (idem, p. 23)". Em que consistiria, segundo Berdiaeff, essa "tragédia do conhecimento"? Ele a explicita e a analisa, discorrendo, ao longo de várias páginas, sobre as relações entre emoção e pensamento, como também entre filosofia e fé. Berdiaeff inicia suas reflexões declarando: 
2 Ao conceituar o conhecimento filosófico como "ato espiritual", no qual convergem "as forças espirituais do homem" na sua totalidade, Berdiaeff está contemplando uma concepção de "espírito" que, por um lado, não se identifica com nenhuma das múltiplas definições de "espírito" presentes na obra de Hegel, mas também não tem nada a ver com o que Mounier critica como uma concepção espiritualista de "espírito desencarnado". Tanto menos vale aqui o reducionismo extremo e elementar do "Dicionário de Filosofia de Cambridge" (Audi, 2006, p. 288), que apenas registra o verbete "Espírito" e remete ao verbete "Alma", identificando "espírito" como outra denominação ou como simplesmente sinônimo de "alma". Talvez se possa dizer de Berdiaeff, o que Ernildo Stein afirmou de Ernani M. Fiori, ao discorrer sobre "a grande metáfora do espírito em Ernani Fiori”. Na "Enciclopédia Filosófica" italiana, lemos: "Para Berdiaeff, que elimina a dualidade cristã de espírito e matéria, o mundo material não é senão epifenômeno do espírito [...] (Centro di Studi Filosofici di Gallarate, 1957, I, p. 639)". Eu observaria que mais do que "dualidade cristã", se trata de dualismo grego e cartesiano.
É, com efeito, um erro crer que a emoção não possa ser senão subjetiva, enquanto que o pensamento seria objetivo; um erro é crer que o sujeito conhecente só entra em contacto com o ser pelo intelecto e que e emoção o mantém no seu universo subjetivo. É a concepção do tomismo, a do racionalismo; era a de quase toda a filosofia grega, que se esforçava de passar da $\delta o \xi \alpha$ à $\varepsilon \pi 1 \sigma \tau \eta \mu \eta$, da opinião à ciência; a da maioria dos filósofos (Berdiaeff, 1961, p. 23).

Nesta linha de pensamento, o autor citado destaca a contribuição de Max Scheler e de "toda a filosofia da existência". Contra o que considera preconceito do objetivismo intelectualista, ele pondera:

A emoção humana está, em grande parte, socialmente objectivada, não é subjectiva, reserva feita a uma parte que se mantém individual. Inversamente, o pensamento pode ser muito subjectivo, e acontece freqüentemente ser ele mais individual que a emoção, depende menos da objectivação social, dos grupos sociais, [...] (idem, p. 24).

A favor da "emoção", no processo do conhecimento, Berdiaeff ${ }^{2}$ argumenta que "o conhecimento filosófico é um acto espiritual, e neste acto, não somente opera o intelecto, mas converge a totalidade das forças espirituais do homem, o seu ser "volitivo" e o seu ser "sensitivo" (idem, p. 24).

O autor observa, em seguida, que há uma tendência, hoje, "a admitir a existência de um conhecimento emocional, como o pensava Pascal [...]”. Como pensadores dos nossos dias, ele cita Max Scheler e Keysserling. De Berdiaeff, não posso omitir aquela que me parece a citação mais importante:

É um preconceito pensar que o conhecimento é sempre racional, que não há conhecimento irracional. Conhecemos muito mais pelo sentimento que pela inteligência: É de notar que não só a simpatia e o amor, mas mesmo a inimizade e o ódio, podem ser auxiliares do conhecimento. O coração está no centro do homem total. Verdade antes de tudo cristã. Todo o lado apreciativo do conhecimento é afectivo, exprime "as razões do coração". Os juízos de valor desempenham um papel extremamente importante no conhecimento filosófico. Porque "o sentido" não pode ser conhecido sem juízos devalor, o conhecimento do Sentido é, antes de tudo, um conhecimento do coração. No conhecimento filosófico é o ser total do homem quem conhece, e é por isso que ao conhecimento vem necessariamente juntar-se a fé. Introduz-se em toda a especulação filosófica, por mais racional que seja; inspirava Descartes, Spinoza, Hegel (Berdiaeff, 1961, p. 23-24).

Confirmando a denúncia de Berdiaeff contra o preconceito de que "não há conhecimento irracional”, cabe 
lembrar, ao menos de passagem, toda a obra de Freud a respeito do inconsciente, como também a de Jung, que em aspectos importantes discorda de Freud. De Jung, parece-me interessante citar aqui dois fragmentos que se completam:

A acentuação que a mentalidade ocidental coloca no objeto fez esquecer que todo o conhecimento da realidade também é condicionado subjetivamente, isto é, psiquicamente. Esta orientação que se manifestou em primeiro lugar no desenvolvimento intelectual da Igreja na forma do platonismo e agostianianismo foi substituída pelo aristotelismo. [...] Nossa atitude intelectualista e racionalista ocidental tornou-se aos poucos um embaraço que causou distúrbios no equilíbrio psíquico a tal ponto que é difícil avaliar no momento. (Jung, 2001, p. 322-323).

Quanto a Jung, numa perspectiva muito diversa da de Freud, importa lembrar que ele conhece profundamente o pensamento oriental, no qual poderíamos encontrar contribuições extraordinárias para a superação do racionalismo ocidental, mas infelizmente pouco reconhecidas ainda no campo acadêmico, no Ocidente. Frente a esse complexo de "superioridade" do Ocidente, parece-me interessante citar um testemunho trazido por Paramahansa Yogananda, em seu famoso livro "Autobiografia de um Iogue". Ele conclui um capítulo sobre um encontro com seu mestre Sri Yukteswar com um depoimento altamente significativo de um amigo, inicialmente bastante cético: "O que acabei de ouvir a respeito dos poderes de nosso guru - disse Dijen - me dá a impressão de que qualquer universidade do mundo não passa de um jardim de infância". (Yogananda, 2008, p. 199).

3 A título de exemplo, como confirmação desta influência, podemos citar dele a obra "A Mente Meditativa” (1997). Em Nota à edição brasileira (idem, p. 7), Daniel Coleman informa "Escrevi $A$ mente meditativa há mais de vinte anos, quando comecei a explorar, como estudante de psicologia em Harvard, os caminhos pouco usuais da mente. Dei-me conta, no curso desses estudos, de que todas as grandes tradições espirituais abrigam em seu íntimo uma teoria e um método psicológicos, meios para enfrentar o grande desafio humano: harmonizar coração e mente. Em época mais recente, comecei a formular esse desafio em termos de "inteligência emocional", trazendo a inteligência para nossas vidas emocionais. E considero os sistemas de meditação das grandes religiões como meios poderosos param lidarmos com nossas emoções, particularmente as emoções aflitivas. Por isso, espero que este pequeno livro proporcione aos leitores brasileiros uma grande paz interior".
Ao salientar as afinidades de Jung com o pensamento oriental, ocorre-me também a lembrança de outro autor, cuja influência oriental é evidente em sua obra, e que é considerado um dos mais importantes entre os pensadores da atualidade que escreveram sobre o lado emocional da inteligência e do conhecimento. Trata-se de Daniel Goleman ${ }^{3}$, autor do livro intitulado precisamente "Inteligência Emocional" (Goleman, 1995).

Ao iniciar suas reflexões sobre "Nossas Duas Mentes", Goleman relata a conversa com uma amiga que lhe falava de seu divórcio. Passados alguns meses de conflitos e mágoas, ela dizia sentir-se bem, e afirmou: "Simplesmente não penso mais nele; na verdade, nem quero saber dele." Mas Goleman observa: "Só que, ao dizer isso, de repente seus olhos ficaram cheios de lágrimas”. E continua:

Aquele lacrimejar de olhos poderia passar facilmente desapercebido. Mas, por um tipo de compreensão que acontece através da 
empatia, os olhos marejados em uma pessoa indicam que ela está triste, não importa o que ela tenha expressado em palavras. A empatia é um ato de compreensão tão seguro quanto a apreensão do sentido das palavras contidas numa página impressa. $\mathrm{O}$ primeiro tipo de compreensão é fruto da mente emocional, o outro, da mente racional. Na verdade, temos duas mentes - a que raciocina e a que sente. - Esses dois modos fundamentalmente diferentes de conhecimento interagem na construção de nossa vida mental. [...] A dicotomia emocional/racional aproxima-se da distinção que popularmente é feita entre "coração" e "cabeça"; saber que alguma coisa é certa "aqui dentro no coração" é um tipo diferente de convicção - tem um sentido mais profundo, ainda que idêntica àquela adquirida através da mente racional. [...] Essas duas mentes, a emocional e a racional, na maior parte do tempo operam em estreita harmonia, entrelaçando seus modos de conhecimento para que nos orientemos no mundo (Goleman, 1995, p. 22-23).

No Apêndice B de seu livro intitulado "Características da Mente Emocional” (idem, p. 305-310), Goleman escreve:

Só recentemente foi elaborado um modelo científico da mente emocional que explica porque muitas de nossas ações são determinadas pela emoção - porque somos tão racionais num determinado momento e tão irracionais em outros - e também foi firmado o entendimento de que as emoções têm uma razão e uma lógica que lhe são tão peculiares. [...] A mente emocional é muito mais rápida que a racional, agindo irrefletidamente, sem parar para pensar. Essa rapidez exclui a reflexão deliberada, analítica, que caracteriza a mente racional (Goleman, 1995, p. 305).

A contraposição "coração/cabeça" tem a ver com o famoso aforismo de Pascal: "O coração tem razões que a própria razão desconhece" (PASCAL, 2006, p. 87). E as contraposições "emocional/racional", "irracional/ racional", nos lembram os binarismos de Berdiaeff. Mas nem em Goleman, como já observei a respeito de Berdiaeff, o "irracional" referido ao conhecimento emocional tem a conotação depreciativa que o termo carrega na linguagem do senso comum.

Citei anteriormente, "en passant", Freud e Jung para reforçar a crítica de Berdiaeff ao preconceito dos que negam a existência de um conhecimento irracional. Cabe esclarecer, porém, que Berdiaeff não se refere ao inconsciente, nem de Freud, nem de Jung. Ele contrapõe, à exclusividade do conhecimento racional, o conhecimento emocional, marcado pelo sentimento, pela emotividade, pelo afeto. No contexto desta discussão, é oportuno citar um texto do filósofo brasileiro Sérgio Paulo Rouanet, cujo 
4 Emmanuel Mounier nasceu em Grenoble em 1905 e faleceu repentinamente em Châtenay-Malabry, cidade periférica de Paris, em 1950. Fundou, em 1932, a famosa até hoje, revista Esprit, em torno da qual foi se estruturando o vigoroso movimento personalista. A maior parte de suas obras está reunida em quatro volumes que perfazem um total de mais de 3000 páginas. Seu livro mais importante intitula-se O Personalismo. Mounier exerceu grande influência, antes das ditaduras militares, sobre os cristãos de esquerda do Brasil, entre eles Paulo Freire, e de outros países da América Latina. É considerado por muitos um precursor leigo do Concílio Vaticano II. Vários intelectuais brasileiros da atualidade escreveram tese de doutorado ou outros estudos sobre a obra de Mounier. título "Razão e Paixão" já diz, de saída, toda a relação com o tema deste artigo (Rouanet, 1988, p. 437-467). Rouanet discute o "conflito - ou diálogo - entre razão e paixão" (idem, p. 437) a partir de uma leitura atenta e minuciosa da peça As bacantes, de Eurípides. Quanto à razão, ele considera a existência, naquela obra de Eurípides, de uma "razão louca" e uma "razão sábia". No intuito de desvendar os diferentes "cruzamentos" da razão com a paixão, ele "cruza", na sua caminhada, com vários grandes pensadores, entre os quais destaco Freud. Erasmo e Kant. Quanto a Freud, ele considera "[...] que mais que ninguém aprofunda os cruzamentos entre a paixão e a razão [...]" (idem, p. 450). Em Erasmo, na sua obra clássica $O$ elogio da loucura, Rouanet (1988, p. 464-465) encontra a descrição mais perfeita da "razão louca", contrapondose à "razão sábia", elaborada com rara inteligência e sutil humor, como só Erasmo saberia fazer. Ao longo do texto, Rouanet se refere várias vezes ao Iluminismo, numa visão muito otimista. À pergunta "O que é o iluminismo?" recorre a Kant para uma definição, talvez a mais abalizada, daquele movimento histórico (Rouanet, 1988, p. 466). Se o Iluminismo foi, como o vê com otimismo Rouanet, como o considerava Kant e, antes dele, Rousseau, nas interações entre a razão e a emoção, eu creio que na sua trajetória o necessário equilíbrio cedeu lugar à absolutização ou hipertrofia da razão, que nos conduziu à atual condição histórica da "anticivilização da barbárie".

Ao discorrer sobre a emotividade no processo do conhecimento, não poderia omitir Mounier ${ }^{4}$, quando ele propõe:

Que seja dedicado a uma reflexão sobre o amor um esforço tão considerável como a aquele que foi consagrado à reflexão sobre o conhecimento e a fortiori, àquele que se destinou à invenção tecnológica, tal é a subversão que o espírito cristão deve inaugurar na pesquisa (Mounieur, 1962, vol. III, p. 594).

Mounier praticou constantemente, ao longo de sua vida, o que propunha em seus escritos. Antes de fundar, em 1932, a revista Esprit, ele se preocupou, primeiramente, de criar um "circuito de amizades atuantes". A uma amiga de Casablanca ele propunha: "Desde agora procure organizar, com algumas pessoas, um grupo baseado na amizade, suscetível de tornar-se um grupo de trabalho." (Mounier, 1963, vol. IV, p. 493-495). Em artigo publicado em 1932 ele já escrevera: "Toda ação é uma ação de presença. [...] É preciso amar o mundo, é preciso amar os homens quando a gente se dedica ao trabalho de manter o intercâmbio com eles.” (Mounier, 1963, vol. IV, p. 10).

Nessa mesma linha de pensamento e de ação, durante a guerra Mounier se preocupou em manter o contato pessoal com os grupos, como escreveu em seu diário, no 
dia 17 de novembro de 1941:

Irei pôr em execução um projeto que minhas sobrecargas de compromissos me impediam após o armistício: o circuito (tour) das amizades. Em Marselha, em Toulon, em Grasse, em Nice, em Toulouse, em Pau, eu os encontrei unânimes (Mouniuer, 1963, vol. IV, p. 720).

A respeito dessa maneira de agir de Mounier, eu já havia escrito, em minha tese de doutorado:

Este trabalho não era puramente administrativo. Mounier colocava nele toda a sua inteligência, mas sobretudo sua capacidade de união (rassemblement), portanto de amor. [...] Os grupos "Esprit", organizados em numerosas cidades da França e do estrangeiro, foram uma das iniciativas mais extraordinárias de que se tenha conhecimento, como pedagogia para a formação de pessoas e como estratégia de continuidade e de eficácia de um movimento. Paulo Fraisse (1950: p. 789) denominou tais grupos "os retransmissores (les relais) de Esprit através do mundo" (Andreola, 1985, p. 145).

Especificamente com relação ao conhecimento e ao processo ensino-aprendizagem, Mounier assume uma posição na linha da gratuidade, da emoção, da amorosidade. Em 1928 escrevia a sua irmã: "[..] perdemos o sentido de doar-se, a própria inteligência tornase uma propriedade, constituindo-se causa de muitas ruínas humanas" (Mounier, 1963, vol. IV, p. 431). A mentalidade do "armazenamento" ou da "acumulação" dos conhecimentos, Mounier a considera como uma postura do "ter", na dualidade ser ou ter. Trata-se, segundo ele, de uma modalidade de posse, que ele denuncia em seu livro "Introdução aos Existencialismos":

O ser é um inesgotável concreto que não pode ser constatado, mas somente reconhecido, como se reconhece uma pessoa, e até mesmo menos reconhecido que saudado. A imagem da posse não chega a estabelecer o contato entre o que conhece e o ser. A gente não possui senão aquilo que é inventariável. Ora, se o ser é inesgotável, ele é, até em sua mais pequenina parcela, o não inventariável. Tudo aquilo que eu acumular de saber a respeito dele (sendo o saber um ter de quem conhece), permanecerá sempre uma quantidade ínfima em relação àquilo que dele ignoro. A Náusea é o mal do homem que quer possuir o mundo, até mesmo no momento em que tem uma vertigem ontológica da vaidade ofuscante desta possessividade. (Mounier, 1962, vol. III, p. 80-81).

O mesmo critério de análise usado por Mounier para denunciar a "mentalidade de posse" com relação ao 
conhecimento, ele utiliza com relação aos valores morais. Sem uma autêntica educação moral, essa mentalidade evoluirá em direção a um moralismo egocêntrico, que apresenta formas as mais banais. Segundo ele:

Suas virtudes são um tesouro contabilizável que é acumulado, que se deposita, protegido por todos os jogos da vaidade, do segredo, dos cálculos, do interesse. Mas, para ter, é preciso guardar, e a moralidade morre quando a gente a coloca num banco. Para contar, precisase de uma medida e a característica da vida moral consiste em que a escala do bom e do mau se eleva a cada progresso, em que um instante de perdão e de amor vale mais do que anos de parcimoniosa acumulação. (Mounier, 1962, vol. III, p. 689-690)

Num sentido diverso do que lhe atribui Freire, poderíamos pensar que se trata de uma "pedagogia bancária", sendo que o "proprietário" dos conhecimentos acumulados ou das virtudes armazenadas os deposita num "banco". Ironicamente, me ocorre associar esta concepção quantitativista e mercantil dos conhecimentos e das virtudes morais a determinados critérios quantitativos usados pelo sistema oficial de educação, ao organizar as disciplinas em forma de "créditos". E não estaria acontecendo algo de semelhante, quando nos perguntamos a respeito do "qualis" da revista em que pretendemos publicar nossos artigos? E a pergunta se torna obrigatória, sendo que as avaliações predominantemente quantitativas de agências que financiam a pesquisa são rigorosas.

Esta "exigência" de "amar o mundo", de que fala Mounier, quando escreve "é preciso", no artigo de 1932, citado anteriormente, lembra-me a última página que Freire nos deixou, na sua "Terceira Carta Pedagógica". Na veemência de sua indignação, perante a crueldade do assassinato do índio Pataxó, ele proclama a exigência de um amor total, ecológico ou até "cósmico", ao declarar:

O acatamento ao outro, o respeito ao mais fraco, a reverência à vida não só humana, mas vegetal e animal, o cuidado com as coisas, o gosto da boniteza, a valoração dos sentimentos, tudo isso reduzido a nenhuma ou quase nenhuma importância. Se nada disso, a meu juízo, diminui a responsabilidade desses agentes da crueldade, o fato em si de mais esta trágica transgressão da ética nos adverte de como urge que assumamos o dever de lutar pelos princípios éticos mais fundamentais como do respeito à vida dos seres humanos, à vida dos outros animais, à vida dos pássaros, à vida dos rios e das florestas. Não creio na amorosidade entre mulheres e homens, entre os seres humanos, se não nos tornamos capazes de amar o mundo (Freire, 2000, p. 207).

Aquele brado final de Freire soou carregado da 
veemência de sua indignação, raiva e repulsa contra a violência total daqueles jovens assassinos. Mas foi também proclamação, não menos intensamente emotiva, do amor à vida em todas as suas expressões.

As dimensões da afetividade, da amorosidade, do sentimento, do amor enfim, perpassam todas as obras de Freire. A categoria do amor aparece reiteradas vezes já em sua obra principal, "Pedagogia do Oprimido", onde ele o estabelece como condição fundamental para o diálogo, e o salienta inclusive como qualidade e norma de vida de revolucionários como Che Guevara e Camilo Torres. Paulo Freire conclui "Pedagogia do Oprimido" com esta frase: "se nada ficar destas páginas, algo, pelo menos, esperamos que permaneça: nossa confiança no povo. Nossa fé nos homens e na criação de um mundo em que seja menos difícil amar" (Freire, 2007, p. 213).

Sem deter-me longamente sobre as dimensões afetivas da obra de Freire, não posso deixar de citar as palavras finais de uma longa entrevista com Claudius Ceccom e Miguel Darcy de Oliveira publicada no jornal "O Pasquim":

[...] Para mim é imprescindível a afetividade e o amor. Eu tenho aliás recebido muitas críticas, sobretudo da América Latina, porque eu falo muito de amor e amor segundo essas críticas é um conceito burguês. Em primeiro lugar eu não admitiria que foram os burgueses que inventaram o amor. Eles podem ter a propriedade das fábricas, mas do amor não. $\mathrm{O}$ amor é uma dimensão do ser vivo e que ao nível do ser humano alcança uma transcendência espetacular. Nesse sentido é que eu digo que a revolução é um ato de amor (Freire, 1978, p. 11).

Naquela mesma entrevista, Freire havia afirmado, como uma das principais aprendizagens do seu exílio: "Eu sou capaz de querer bem, enormemente, a qualquer povo".

Meu interesse em discutir as dimensões emotivas ou afetivas do conhecimento, em oposição ao intelectualismo ou racionalismo extremo da modernidade, obedece a preocupações pedagógicas, mais do que apenas filosóficas. Concretamente, não pode acontecer um processo adequado de ensino-aprendizagem ou de educação, num sentido mais estrito, sem um clima de relações afetivamente positivas.

Grupos de estudos ou de pesquisa nunca se constituem sem basear-se em relações de simpatia e de amizade. O próprio Mounier, escrevendo aos companheiros do movimento personalista e da revista Esprit, propunha que se organizassem primeiramente em "grupos de amizades atuantes", antes de atuarem propriamente como grupos de estudo.

Em termos de bases afetivas para uma educação 
adequada, julgo oportuno trazer o exemplo de uma Congregação Religiosa, que estabelece, como um de seus princípios básicos, "a educação do coração". Faço esse registro como referência a um estudo meu já publicado (Andreola, 2005, p. 167-180), e como antecipação de um artigo que estou escrevendo para a revista italiana "Prospettiva/Persona". A Congregação surgiu, no século XIX, dedicando-se inteiramente à educação de jovens pobres e desamparados. Inspirado no bispo e professor universitário Félix Dupanloup, o fundador, Leonardo Murialdo, deixou escrito:

O sistema proposto tem seu fundamento no princípio de Dupanloup: "O educador tem a seu cuidado e como finalidade o que há de mais precioso na sociedade, isto é, as crianças; aquilo que há de mais precioso nas crianças, o coração, não tanto o exterior, o comportamento visível, a tarefa, a escola, mas sim o interior, o coração, a religião e a educação dos sentimentos.” (Dotta \& Fossati, 2012, p. 241)

Emotividade, sentimento, afetividade, como elementos essenciais no processo do conhecimento e da educação, expressam-se em diferentes terminologias na vida e nas obras de grandes personalidades políticoproféticas, como as que cito em minha "Carta-Prefácio" ao livro póstumo de Freire intitulado "Pedagogia da Indignação" (Freire, 2000, p. 24), e cujos nomes retomo num artigo recente (Andreola, 2011, p. 322), com o acréscimo de alguns outros. São eles: M. Gandhi, João XXIII, Luther King, Simone Weil, Lebret, Franz Fanon, Che Guevara, Teresa de Calcutá, Dom Hélder, Dom Ivo Lorscheider, João Paulo I, E. Mounier, Teilhard de Chardin, Nelson Mandela, Roger Garaudy, Dalai Lama, Téovérdjré, Betinho, Paramhansa Yogananda, Michel Duclerq, Fritjof Capra, Pierre Weil, Leonardo Boff, Paul Ricoeur e outros. De todas essas personalidades, basta lembrar que foram profundamente amorosas. Ao nomear essas personalidades do nosso tempo, minha preocupação foi a de dizer que não considerava Freire uma voz isolada ao propor "Pedagogia do Oprimido" como projeto de um mundo mais solidário, mas que, pelo contrário, eu o via na "constelação" de numerosas lideranças mundiais que "convergiam", como ele, na luta por um novo processo civilizatório mais humano.

Um dos elencados acima, Leonardo Boff, em vários de seus livros adota, como conceito-chave, o "cuidado", presente já no título de um deles: "Saber Cuidar: Ética do humano - compaixão pela Terra". A categoria "cuidado" o autor busca em Heidegger, em sua obra clássica "O Ser e o Tempo". Para o sentimento de "compaixão" ele se inspira, creio, no Dalai Lama (2000). De Leonardo Boff, do volume II de seu livro "Virtudes para um outro mundo possível", destaco o título "Convivência: aproximar-se, 
ver, compadecer-se e cuidar". Depois de salientar, como primeiro momento o despojamento, escreve:

O segundo momento é de cuidado. O cuidado se expressa pela saída de si em direção do outro e se traduz em solidariedade, em serviço e em hospitalidade para com o outro. Vale dizer, sofrer com quem sofre. Mas também alegrar-se com quem se alegra. Implica co-mungar, caminhar juntos, conviver, oferecendo-se mutuamente o ombro e dando-se as mãos (Boff, 2006, p. 26).

Dos pensadores/educadores da humanidade lembrados acima, além de alguns já citados, acho de fundamental importância lembrar ainda Paul Ricoeur, transcrevendo o que já escrevi num artigo anteriormente citado (Andreola, 2011, p. 324).

Dos nomes citados na constelação das "convergências" em que vejo Freire, lembrarei agora dois, pois são uma convergência de grande importância histórica. Trata-se de N. Mandela e de P. Ricoeur. Mandela, o grande líder da luta contra o apartheid, na África do Sul, foi o principal responsável pela Comissão da Verdade e Reconciliação, trazida por Ricoeur como o exemplo mais importante, talvez o único, na história da humanidade, do que ele denomina “perdão difícil” (Ricoueur, 2007). Ao publicar no ano 2000 sua obra La Mémoire, L'Histoire, L'Oubli, agora em português (2007), acrescentou àquela edição o "Epílogo o perdão difícil" (2007, p. 463-513), escrito sob a sensação da "urgência". O "perdão" difícil, que aconteceu na África do Sul através de um processo nacional de reconciliação, Ricoeur o distingue radicalmente de um processo de "anistia", como o que aconteceu melancolicamente no Brasil, no ocaso da ditadura. Ao trazer no "epílogo" de seu livro, o exemplo da África do Sul, Ricoeur mostrou ser possível que a utopia se concretize na história. Anos antes ele propusera, num artigo memorável (Ricouer, 1992), a utopia de um "perdão difícil" como a única saída para a Europa, envolta em ódios milenares, que periodicamente prorrompem em guerras cruéis.

Um intelectual e educador amplamente reconhecido entre nós, cuja vasta obra literária está ensopada de poesia, imaginação, emotividade e amorosidade é Rubem Alves. Dele tratarei, na brevidade desse artigo, ao menos de um texto. Depois de citar um fragmento da escritora Maria Antônia de Oliveira, no qual ela fala de "cacos de vida" ou de memória, Rubem Alves escreve:

É com esses cacos de memória, pedaços de nós mesmos, que se escrevem romances, estórias infantis, poesia, lendas, mitos religiosos, utopias. Nietzsche dizia que só amava os livros escritos com essas memórias, escritos com sangue. E Guimarães Rosa dizia a seus leitores que, para ser escritor, é preciso conhecer a alquimia do sangue do coração 
humano. Ler um livro escrito com sangue é participar de um ritual antropofágico. É uma celebração eucarística (Alves, 2005, p 15-16).

Vários dos autores que eu vim citando ao longo deste escrito não são muito aceitos na academia, ou até proibidos por alguns orientadores para seus orientandos, com a justificativa de que não são rigorosamente científicos. No livro "Encantar o mundo pela palavra", escrito num diálogo prazeroso entre Rubem Alves e Carlos Rodrigues Brandão, o primeiro, a certa altura, diz: "Conheço pessoas que foram penalizadas em bancas por me citar". Brandão responde: "Também conheço". E Rubem Alves explica: "E a razão para isso é que não sou cientista, sou apenas um escritor" (Alves \& Brandão, 2006, p. 99). Essa acusação acadêmica de falta de rigor científico atingiu também Paulo Freire. Na Introdução às "Notas", escritas, a pedido de Paulo, ao seu livro "Cartas a Cristina", sua esposa Ana Maria Araújo Freire escreveu que alguns de seus leitores cobravam dele a "sistematização" de seu pensamento teórico, político e pedagógico. E ela explica que

[...] ele negou, aos que assim cobraram,
porque pensa deforma diferente o que aqueles
e aquelas entendem por sistematização, essa
pretensão ou essa exigência meramente
formal. - Negou "poetizando" e negou
escrevendo "cartas". Ambas essas negações
são, obviamente, aparentes ne-gações. Essas
formas de dizer de Paulo não impedem
ou distorcem a sistematicidade de seu
pensamento teórico-prático. (ARAUJO
FREIRE, 1994: p. 238).

O grande pecado intelectual desses autores é o de se autorizarem, em suas obras, a criar espaço para as razões do coração, através de uma linguagem difícil de aprisioná-las nos cânones da razão pura. Conceitos, categorias filosóficas são tentativas de captar fragmentos da verdade. Anísio Teixeira dizia: "Não me cobrem coerência com minhas idéias". A primeira vez que li essa frase, fiquei chocadíssimo. Aos poucos fui entendendo que as ideias são tentativas, legítimas sim, mas parciais e provisórias, de aproximação da verdade, não pretensões de captá-la por inteiro, tanto menos de aprisioná-la na gaiola de um conceito, de uma categoria, de uma teoria. As ideias, fragmentos de verdade, são pássaros. Suas asas não sejam, talvez, conceitos, mas metáforas. Deixemo-las voar...

Quando achei que já poderia ir concluindo meu artigo, fiz uma dupla descoberta, que me abriu novos horizontes de reflexão e de diálogo. Ao sair de casa, em Porto Alegre, quis pegar um livro, para ler algo no Metrô que me levaria a Canoas. Mas me deparei com outro, cujo título tinha a ver com a temática de meu artigo: "Vínculo afetivo e aprendizagem", de Nelnie Viale Lorenzoni. Eu nunca tinha folheado ainda aquele livrinho, por dois preconceitos, creio. Primeiro, porque me fora oferecido, ao que parece, por um 
político, aliás muito sério. Mas meu preconceito levou-me a pensar que o "presente" teria fins eleitoreiros. O segundo preconceito ligava-se ao tamanho: um "livrinho", afinal, como tantos outros. Ao abri-lo, já no ônibus que me levaria à estação do trem, encontrei um cartão da autora. Na viagem de poucos minutos de ônibus, e nos treze em que o trem me levaria até Canoas, enquanto folheava o "livrinho", fui rapidamente vencendo meus dois preconceitos. Chegando à minha sala, na UNILASALLE, telefonei para a autora, expressando a emoção que me surpreendera, na descoberta de seu pequeno grande livro, no qual eu sentia em perfeita harmonia a razão e a emoção. A razão estava presente na consistência teórica e metodológica do que a autora escrevera, enquanto a emoção permeava tanto na práxis pedagógica relatada, de professora apaixonada, quanto nos referenciais de primeira qualidade nos quais fundamenta a importância das emoções nos processos do conhecimento em geral, e de ensino/aprendizagem, em particular. Um dos autores mais valorizados é Humberto Maturana, em seu livro "Emoções e linguagem na educação e na política". Para o tema deste artigo, destacarei uma citação que autora extrai da página 81, da edição de 1999. Eu trarei, como referência, a reimpressão de que disponho de 2002:

Vivemos uma cultura que desvaloriza as
emoções em função de uma supervalorização
da razão, num desejo de dizer que nós, os
humanos, nos distinguimos dos outros
animais por sermos seres racionais. Mas
acontece que somos mamíferos e, como
tais, somos animais que vivem na emoção.
As emoções não são algo que obscurece o
entendimento, não são restrições da razão:
as emoções são dinâmicas corporais que
especificam os domínios de ação em que nos
movemos. Uma mudança emocional implica
uma mudança de domínio de ação. Nada nos
ocorre, nada fazemos que não esteja definido
como uma ação de um certo tipo por uma
emoção que a torna possível (Maturana,
2002, p. 92).

Minha surpresa maior não se limitou, porém, à descoberta do livro. A autora me convidou a participar do " 3 " Simpósio Internacional de Justiça Restaurativa - Abordagens Transdisciplinares", cuja abertura seria naquele dia, 29 de outubro, e que continuaria todo o dia seguinte. Dados os meus compromissos acadêmicos, só pude participar na manhã do dia 30. O suficiente, porém, para descobrir um movimento extraordinariamente inovador, que está acontecendo no campo da Justiça, aqui entre nós, e em outros países, como os Estados Unidos e o Canadá. Naquela manhã pude ouvir duas conferencistas daquele simpósio, ambas norte-americanas: Carolyn Boyes-Watson e Saira Pinto. Ambas foram muito brilhantes em suas explanações, mais do que isso, demonstraram um compromisso competente e apaixonado com um processo 
de transformação da justiça, na perspectiva da "Justiça Restaurativa”. As várias intervenções nos debates deixaramme claro que este processo de mudança está sendo amplo e vigoroso também entre nós. Numa intervenção minha, fiz questão de expressar a surpresa muito prazerosa de constatar, nas duas explanações, uma linguagem que sequer imaginava presente no campo do Direito e da Justiça, que eu conheço apenas por uma linguagem altamente técnica, racional e formal. Salientei, em minha fala, palavras como: "sentimentos de empatia, simpatia, compaixão, perdão, amor", emocionalidade (não apenas racionalidade!), coração aberto, conectividade, participação, esperança, perdão, amor. Carolyn Boyes-Watson referiu-se a um "sistema de justiça que se caracteriza por uma negação sistemática do ser humano, da empatia...”. Numa frase fortíssima, denunciou: "A tragédia do nosso sistema de justiça é que exige que se deixe o coração em casa”.

Não caberia delongar-me, nos limites de um artigo, sobre mais detalhes daquele " 3 o Simpósio Internacional de Justiça Restaurativa”. Achei importante, porém, registrar que existe um movimento amplo preocupado em instaurar, ou então "restaurar", também no campo da Justiça e do Direito, um espaço para as "razões do coração". Nesta perspectiva de mudança, não poderia omitir uma informação surpreendente, trazida pela conferencista Saira Pinto. Depois de citar Paulo Freire e seu livro "Pedagogia do Oprimido", informou que está sendo escrito, por um grupo de cientistas, um livro intitulado "Teoria Geral do Amor".

A trajetória percorrida através deste artigo foi para mim uma aprendizagem que venho tentando há muito tempo. Toda a minha educação, toda a minha formação acadêmica, incluindo a filosofia, a teologia e o mestrado em educação, foi um exercício rigoroso da razão pura. $\mathrm{Na}$ minha tese de doutorado permiti-me estabelecer uma interlocução com dois pensadores, Emmanuel Mounier e Paulo Freire, que, através de toda a sua existência e de sua obra, souberam conciliar os rigores da razão com as razões do coração. Neste artigo acrescentei as preciosas contribuições deles às de vários outros pensadores altamente abalizados como eles. Concluirei, pois, este artigo como concluí minha tese de doutorado, com a preocupação de acrescentar a referência a esses outros mestres do pensar que trouxeram luzes para minha caminhada:

A meditação das obras dos pensadores que estudei em minha tese de doutorado, e de outros que me iluminaram na elaboração deste artigo, nos convidam a estabelecer, a exemplo deles, a coerência entre a reflexão e a ação, o pensamento e a vida, a emotividade e a racionalidade, o cérebro e o coração.

\section{EPÍlOGO}

Meu artigo está pronto. Mas preciso acrescentar este 
epílogo. O motivo? A morte de Oscar Niemeyer, ocorrida em 2012. Naquele mesmo ano, o jornal Zero Hora de Porto Alegre dedicou duas páginas à memória do imortal arquiteto. Entre as fotos que ilustram a reportagem, está a do "Memorial da América Latina" - uma mão aberta, de sete metros de altura. E o jornal traz a explicação:

O empreendimento projetado em 1989 foi criado com o objetivo de reunir, em São Paulo, as mais expressivas manifestações culturais do continente. Segundo o arquiteto, a escultura de concreto com sete metros de altura, com o mapa do continente de onde escorre sangue (foto acima), foi o que criou com mais satisfação. A obra significa, segundo Niemeyer, um protesto contra a América Latina sacrificada (Zero Hora, 2012, p. 4-5).

Aquela mão aberta, com o mapa da América Latina jorrando sangue, proclama, com patética sublimidade, tudo o que tentei dizer neste artigo sobre "Emotividade e Razão”. A eminência quase etérea da razão e o vigor da emotividade, o esplendor da inteligência e a veemência do sentimento se juntam, naquele protesto solene e eterno, preconizando a síntese harmoniosa entre o cérebro e o coração, que somente grandes personalidades como Niemeyer conseguem realizar.

\section{REFERÊNCIAS}

AJURIS, $3^{\circ}$ JRIJ-POA/RS, SJDH/RS, PMPA/SMGL,ONG IICR. $3^{\circ}$ Simpósio Internacional de Justiça Restaurativa: Abordagens Transdisciplinares. Porto Alegre/RS, Auditório do Ministério Público, 29 e 30 de outubro de 2012.

ALVES, Rubem. O Velho que acordou menino. São Paulo, Planeta, 2005.

ALVES \& BRANDÃO. Encantar o Mundo com a Palavra. Campinas - SP. Papirus, 2006.

ANDREOLA, Balduino A. Emmanuel Mounier et Paulo Freire: Une Pédagogie de la Personne et de la Communauté. Thèse doctorale. Louvain-la-Neuve (Belgique), Université Catholique de Louvain, 1985.

ANDREOLA, Balduino A. Por uma pedagogia das grandes urgências planetárias. Educação, vol. 36, n. 2. p.313-330, maio/ago. 2011.

ANDREOLA, Balduino A. Dimensões pedagógicas do personalismo de Mounier. In: Revista Filosófica Brasileira. $\mathrm{n}^{\circ}$ 1., p. 55-75.Dez.1990.

ANDREOLA, Balduino A. Pedagogia Murialdina e la Scienza pedagogica. In: BISSONI, Angelo, LAZZARI, Celmo \& AGAZZI, Alessandro (Org.). Per tenere vivo Il pensiero pedagogico: Atti del Seminário della Famiglia Murialdo 
- Fazenda Souza (Brasile), Roma (Itália), Libreria Editrice Murialdo, 2005.

ASSOCIATION DES AMIS D'EMMANUEL MOUNIER. Bulletin des Amis d'Emmanuel Mounier. N. ${ }^{\circ} 4$. Châtenay-Malabry, 1954

AUDI, Robert (org.) et al. Dicionário de Cambridge. Trad. de Edwino Aloysius Royer. São Paulo: PAULUS, 2006.

DALAI LAMA. Uma Ética para o Novo Milênio. $5^{\mathrm{a}}$ ed. Rio de Janeiro, Sextante, 2000.

DALAI LAMA. Bondade, Amor e Compaixão. Trad. Cláudia Gerpe Duarte. São Paulo, Pensamento, $10^{\mathrm{a}}$ ed. 1997.

BERDIAEFF, Nicolau. Cinco Meditações sobre a Existência: Solidão, Sociedade e Comunidade. Trad. de Ana Hatherly. Lisboa, Guimarães Editores, 1961.

BERDIAEFF, Nicolas. 5 Méditations sur L'Existence: Solitude, Société et Communauté. Traduit du russe par Irène Vildé-Lot. Paris, Editions Montaigne, 1936.

BOFF, Leonardo. Virtudes para um outro mundo possível - Vol II: Convivência, Respeito \& Tolerância. Petrópolis, Vozes, 2006.

BOFF, Leonardo. Saber Cuidar: Ética do humano - compaixão pela terra. $2^{\text {a }}$ ed. Petrópolis, Vozes, 1999.

CECCON, Claudius ; OLIVEIRA, Miguel Darcy. Paulo Freire, no exílio, ficou mais brasileiro ainda (Entrevista com Paulo Freire). In: O Pasquim: $n^{0}$ Especial 2: As Grandes Entrevistas Políticas. Rio de Janeiro, $\mathrm{n}^{0}$ 462, 1978. p. 7-11.

CENTRO DI STUDI FILOSOFICI DI GALLARATE. Enciclopedia Filosofica. Vol. I. Venezia - Roma, Istituto per la collaborazione culturale, 1957.

DOTTA, Giovenale \& FOSSATI Giuseppe (orgs.). Antologia delle Fonti Carismatiche: L'insegnamento di San Leonardo Murialdo. Roma, Libreria Editrice Murialdo, 2012.

FRAISSE, Paul. La puissance d'accueil. In: Esprit. Paris, déc. 1950, p. 788-793.

FREIRE, Paulo. Pedagogia da Indignação: Cartas Pedagógicas e outros escritos. Apresentação de Ana Maria Araújo Freire. Carta-Prefácio de Balduino A. Andreola. São Paulo. Edit. UNESP, 2000.

FREIRE, Paulo. Pedagogia do Oprimido. Prefácio de Ernani M. Fiori. 46ª Ed. São Paulo. Paz e Terra, 2007.

FREIRE, Paulo. FREIRE, Paulo. Cartas a Cristina. Pre- 
fácio de Adriano S. Nogueira. Notas de Ana Maria Araújo Freire. Rio de Janeiro, Paz e Terra, 1994.

FREIRE, Paulo. Entrevista, in: CECCON, Claudius ; OLIVEIRA, Miguel Darcy. Paulo Freire, no exílio, ficou mais brasileiro ainda In: O Pasquim: $\mathrm{n}^{\circ}$ Especial 2: As Grandes Entrevistas Políticas. Rio de Janeiro, $n^{0}$ 462, 1978. p. 7-11.

GALEANO, Eduardo. O Livro dos Abraços. Porto Alegre: L\&PM, 1995.

GOLEMAN, Daniel. A Mente Meditativa: As diferentes experiências meditativas no Oriente e no Ocidente. Trad. de Marcos Bagno. $5^{\mathrm{a}}$ ed. São Paulo - SP, Ática, 1997.

GOLEMAN, Daniel. Inteligência Emocional: A Teoria Revolucionária que redefine o que é ser inteligente. Trad. Marcos Santarrita. Rio de Janeiro - RJ, Objetiva, s/d.

JUNG, Carl Gustav. Cartas de C.G Jung. Trad. Edgar Orth. Petrópolis, Vozes, 1999.

LORENZONI, Nelnie Viale. Vínculo afetivo e aprendizagem. Porto Alegre. Edições EST, 2004.

MTURANA, Humberto. Emoções e linguagem na educação e na política. Trad. de José Fernando Campos Fortes. Belo Horizonte, Ed. UFMG, 2002.

MOUNIER, Emmanuel. Oeuvres. Vol. III, Paris, Seuil, 1962.

MOUNIER, Emmanuel. L'Action Intellectuelle ou de l'Influence. Revue de culture générale. Aix-enProvence; Une série: 20 oct., 20 nov., 20 déc. 1931; 20 janv. et 20 mai 1932.

MOUNIER, Emmanuel. Mounier et sa Génération. In: Oeuvres, Vol. IV, Paris, Seuil, 1963.

PASCAL, Blaise. Pensamentos. Introdução e notas de Ch.-M. Des Granges. Trad. de

Sérgio Milliet. Vol. XVI, São Paulo, Abril Cultural, 1973.

PASCAL, Blaise. Do Espírito Geométrico \& Pensamentos. Tradução de Antonio Geraldo da Silva. São Paulo: Escala, 2006.

REALE, Giovanni \& ANTISERI, Dario. História da Filosofia - De Spinoza a Kant. Trad. Ivo Storniolo. $2^{\text {a }}$ edição. São Paulo: Paulus, 2005.

RICOEUR, Paul. O Perdão Difícil (Epílogo). In: A memória, a história, o esquecimento. Tradução: Alain François et al. Campinas, Editora da UNICAMP, 2007. p. 463512. 
99 EMOTIVIDADE VERSUS RAZÃO NO PROCESSO DO CONHECIMENTO

RICOEUR, Paul. Il nuovo ethos per l'Europa. In: Prospettiva/persona, n. 1/2. Teramo (Itália), Edizioni Demian, p. 15-21, luglio/dicembre, 1992.

ROUANET, Sergio Paulo. Razão e Paixão. In: NOVAES Adauto (Org.) et alii. Os Sentidos da Paixão. São Paulo, Editora Schwarcz, 1988. p. 437-467.

YOGANANDA, Paramahansa. Autobiografie de um Iogue. Editio Princeps - Conforme texto original publicado em 1946. Prefácio de W. Y.Evans-Wentz, M.A., D. Litt., D. SC. Trad. de Antonio Olinto, da Academia Brasileira de Letras e Lucia Sweet-Lima. Tadução das poesias: Luiz Carlos Lisboa. $2^{\mathrm{a}}$ ed. Rio de Janeiro, Lótus do Saber, 2008.

ZERO HORA. Oscar Niemeyer - Reportagem Especial. Porto Alegre, 6 de dezembro de 2012: p. 4-5. 